\title{
Cocaine Self-Administration Abolishes Associative Neural Encoding in the Nucleus Accumbens Necessary for Higher- Order Learning
}

\author{
Michael P. Saddoris ${ }^{1}$ and Regina M. Carelli ${ }^{1,2}$ \\ ${ }^{1}$ Department of Psychology, University of North Carolina, Chapel Hill, NC 27599 \\ ${ }^{2}$ Neuroscience Center, University of North Carolina, Chapel Hill, NC 27599
}

\begin{abstract}
Background-Cocaine use is often associated with diminished cognitive function, persisting even after abstinence from the drug. Likely targets for these changes are the core and shell of the nucleus accumbens (NAc), which are critical for mediating the rewarding aspects of drugs of abuse as well as supporting associative learning. To understand this deficit, we recorded neural activity in the NAc of rats with either a history of cocaine self-administration or controls while they learned Pavlovian first- and second-order associations.
\end{abstract}

Methods-Rats were trained for 2 weeks to self-administer intravenous cocaine or water. Later, rats learned a first-order Pavlovian discrimination where a CS+ predicted food, and a control CSdid not. Rats then learned a second-order association where, absent any food reinforcement, a novel cue (SOC+) predicted the $\mathrm{CS}+$ and another (SOC-) predicted the $\mathrm{CS}-$. Electrophysiological recordings were taken during performance of these tasks in the NAc core and shell.

Results-Both controls and cocaine-experienced rats learned the first-order association, but only controls learned the second-order association. Neural recordings indicated that core and shell neurons encoded task-relevant information that correlated with behavioral performance, while this type of encoding was abolished in cocaine-experienced rats.

Conclusions-NAc core and shell perform complementary roles in supporting normal associative learning, functions that are impaired following cocaine experience. This impoverished encoding of motivational behavior, even after abstinence from the drug, may provide a key mechanism to understand why addiction remains a chronically relapsing disorder despite repeated attempts at sobriety.

\section{Keywords}

natural reward; drug abuse; second-order conditioning; electrophysiology; striatum; dopamine

(C) 2013 Society of Biological Psychiatry. Published by Elsevier Inc. All rights reserved.

Corresponding author: Regina M. Carelli, PhD, CB\#3270 Davie Hall, Department of Psychology, University of North Carolina, Chapel Hill, Chapel Hill, NC 27599, rcarelli@unc.edu.

Financial Disclosure: The authors report no biomedical financial interests or potential conflicts of interest.

Publisher's Disclaimer: This is a PDF file of an unedited manuscript that has been accepted for publication. As a service to our customers we are providing this early version of the manuscript. The manuscript will undergo copyediting, typesetting, and review of the resulting proof before it is published in its final citable form. Please note that during the production process errors may be discovered which could affect the content, and all legal disclaimers that apply to the journal pertain. 


\section{INTRODUCTION}

Frequently in addiction, persons persist in drug-taking behavior despite knowledge that these actions may result in negative outcomes. As such, addicted persons may have subtle but important deficits in learning, which can manifest when situations demand flexibly altering habitual actions to avoid relapse, or select behaviors that will maximize long-term goals over short-term desires of drug-taking. This pattern strongly implicates alterations in the functions of limbic circuits, particularly the ventral striatum and associated regions [1$6]$.

Indeed, situations may not be selective to drug-related activities, but may extend to changes in learning and behaviors related to "natural" rewards such as food. For example, rats with a history of cocaine experience are unable to alter an associatively-learned behavior when a previously rewarding food outcome is devalued through illness [7] and are impaired at flexibly altering behaviors in reversal tasks [8-10]. Further, repeated exposure to drugs can strongly potentiate the ability for previously rewarding cues to invigorate on-going operant behavior even in non-drug contexts [11-13].

The nucleus accumbens (NAc) is implicated in integrating associative information and reward from limbic circuits, and using this information to guide appropriate action. Lesions of the NAc have been associated with profound deficits in motivated behavior and decisionmaking [14-20], while neurons in the NAc encode important information about rewardpredictive cues and actions [21-25]. Indeed, this encoding is quite sophisticated, and tracks not only the association between cues and outcomes, but also the costs and values associated with various actions $[26,27]$ and higher-order interactions between previously learned sets of information [13]. The NAc is also a primary target for drugs of abuse like cocaine, which acts by inhibiting reuptake of dopamine (DA) from the synapses. Given the strong modulatory role that DA plays in shaping neural signaling, it is likely that repeated exposure to elevated synaptic DA may have profound effects on NAc cellular efficacy [28, 29].

However, little is known about how prior exposure to cocaine affects NAc-dependent associative learning for natural rewards. To understand this, we employed a Pavlovian second-order discrimination, a higher-order behavioral task in which animals must use the acquired value of one cue to support learning about another cue [30, 31]. Specifically, animals initially learn a first-order association in which one cue (CS+) is paired with food while a second cue (CS-) is not. Next, absent food reinforcement, rats learn the second order association whereby a novel cue (SOC+) predicts the $\mathrm{CS}+$ and another cue (SOC-) predicts the CS-. This NAc-dependent task $[32,33]$ has the benefit of containing distinct phases of acquisition and expression of associative learning, and as such can reveal critical differences between simple learning, reward processing and higher-order cognitive processing. Further, we recorded neurons in NAc core and shell of rats with a history of cocaine self-administration or controls while they performed the task. Controls learned this task and showed task-relevant encoding in the NAc that predicted accurate behaviors; remarkably, cocaine-experienced rats failed to learn the higher-order (but not first-order) discrimination, an effect mediated by the abolishment of associative encoding in the core and shell.

\section{METHODS AND MATERIALS}

Detailed methods are described in the Supplemental Methods. Briefly, male SpragueDawley rats $(\mathrm{n}=19)$ were used. Rats were prepared with indwelling jugular catheters as described previously [13] and trained to self-administer either IV cocaine or water to a foodcup (while receiving yoked vehicle [saline] infusions IV). Later, all rats were surgically 
prepared for electrophysiological recordings in the NAc core and shell [13], and one week later trained on a first-order Pavlovian discrimination task where one cue $(\mathrm{CS}+)$ was predictive of food, while a control stimulus (CS-) had no programmed consequences. Rats were then tested on a second-order schedule where a new cue (SOC+) was immediately followed by the $\mathrm{CS}+$, and another cue (SOC-) was followed by the $\mathrm{CS}-$ (Figure 1A). Conditioning was assessed using automated measures of outcome approaches to the foodcup during the cues relative to baseline entries. During select days, electrophysiological recordings were made from the core and shell of the NAc while the rats performed the task, and encoding was determined by examining whether neural firing phasically changed in relation to the delivery of events (i.e., cues, reward delivery).

\section{RESULTS}

\section{Cocaine Experience Impairs Second-Order, but not First-Order Conditioning}

During self-administration sessions, rats in the cocaine-administering group lever pressed $15.0 \pm 2.5$ times per session over $14 \pm 1.5$ days. Rats in the water group pressed 19.0 \pm 4.7 times per session over 14 days, a pressing rate which was not significantly different than cocaine administering rats, $\mathrm{t}_{(12)}=0.67, \mathrm{p}=0.48$. Thus, rats in both of these groups received similar amounts of lever pressing and experience with the audio-visual cue during training.

Rats then performed the first-order Pavlovian discrimination task in which the CS+ was paired with food and the CS- was not, as described above (Figure 1A). Animals in the control (saline and drug-naïve rats; Figures 1B and S1) and cocaine (Figure 1C) groups rapidly acquired the first-order contingency, and were increasingly able to accurately discriminate between the cue types across days, (cue $X$ day, $F_{(9,306)}=20.34$, $p<0.0001$ ). Importantly, cocaine experience had no effect on first-order associative learning, as there were no differences in responding between cocaine rats and controls during either CS or baseline on any day, (cue $\mathrm{X}$ drug, $\mathrm{F}_{(1,17)}=1.90$, $\mathrm{p}=0.19$; cue $\mathrm{X}$ drug $\mathrm{X}$ day, $\mathrm{F}_{(9,153)}=1.63$, $\mathrm{p}=0.11$ ); all pairwise post-hoc comparisons between cocaine and controls on each day, $\mathrm{p}>0.90$. Rats showed more responding during the later portion of the CS+ presentation, consistent with previous findings [34], though this was not different between groups (Figure $\mathrm{S} 2$ ). Finally, rats in both groups showed similar rates of responding to obtain food as there were no main effects or interactions with cocaine history (both $p>0.18$ ) during the reward period, suggesting cocaine experience had no effect on the motivation to obtain delivered food reinforcers.

We then tested the ability for the same rats to use this first-order information to acquire a new second-order association (Fig 1A, bottom). Critically, no food was delivered following the SOC stimuli, so rats were required to use the acquired value of the CS+ to support this new learning. In contrast to first-order conditioning, cocaine-treated rats showed a markedly impoverished ability to acquire the second-order association. While controls displayed differential responding to the SOC cues, rats in the cocaine group failed to do so, as demonstrated by a main effect of drug, $\mathrm{F}_{(1,15)}=4.76, \mathrm{p}<0.05$, and an interaction of cue $\mathrm{X}$ drug, $F_{(1,15)}=9.04, p<0.01$ (Figures 1D and 1E). Planned comparisons for rats in the cocaine group showed a transient increase in responding to the SOC+ over SOC- on day $1(\mathrm{p}<0.03)$ but disappeared by SOCD2 and SOCD3, when all cue responding vs baseline was absent.. In contrast, control rats showed a significant increase in foodcup entries during the SOC+ compared to both baseline and SOC- on all days of test (all comparisons vs SOC+, all $\mathrm{p}<0.0005)$, while showing no differences in responding between SOC- and baseline on any day (all SOC- vs baseline, $\mathrm{p}>0.90$ ). Further, SOC+ responding in controls showed a trend towards greater responding on SOCD1 compared to cocaine rats, $(\mathrm{p}=0.07)$, and significantly higher responding than cocaine rats on SOCD2 $(\mathrm{p}=0.03)$ and SOCD3 $(\mathrm{p}<0.005)$. In contrast, $\mathrm{SOC}-$ responding was not different between groups on any day (all $\mathrm{p}>0.50$ ). 
The degree of cocaine experience was important for these behaviors. A subset of rats $(n=3)$ had only limited access to cocaine (less than $7 \mathrm{~d}$ of self-administration) during training. These rats showed normal rates of learning and cue discrimination in both first-order (Figure S3, middle top) and second-order (Figure S3, middle bottom) conditioning paradigms. Thus, it was not necessarily exposure to cocaine itself, but repeated access to the drug that had the most deleterious effects on higher-order learning.

Intriguingly, cocaine did not abolish all conditioning in these sessions. Immediately following each SOC cue, rats received the associated FOC cue (i.e., the previouslyconditioned CS+ or CS- cue). Both cocaine and control rats responded at similar rates during the $\mathrm{FOC}+$, and as such there were no main effects of cocaine, $\mathrm{F}_{(1,15)}=0.08$, $\mathrm{p}=0.78$, or interactions of cocaine by other factors, (all ANOVA interactions, $\mathrm{p}>0.10$ ). Indeed, pairwise comparisons of the effect of day indicate that both groups showed reliable increases in foodcup responding during the FOC+ compared to both baseline and FOC- (all comparisons $\mathrm{p}<0.01$ ), with no differences between FOC- and baseline on any day (all comparisons $\mathrm{p}>0.49$ ). Thus, cocaine did not generally impair behavioral performance, but was selective to Pavlovian second-order discriminations.

\section{Cocaine Experience Does Not Affect Reward Encoding by NAc Neurons}

During conditioning, cells were electrophysiologically recorded while rats performed the first-order and second-order behavioral tasks. Neural activity was recorded from wires in the NAc core and shell subregions of both cocaine ( 50 wires core, 47 shell) and control (42 wires core, 31 shell) rats (Figure S4). In cocaine rats, 202 recordings were made from neurons in the core and 150 recordings in the shell. For controls, 104 recordings were taken from the core and 154 from the shell.

Reward encoding was first analyzed to determine if cocaine fundamentally affected the manner in which the natural food reward was processed by NAc neurons. To test this, we examined the subset of neurons that selectively encoded the reward (i.e., showed phasic firing changes at reward delivery after CS+ trials compared to the corresponding time following CS- trials when no reward was delivered; Figure 2A). Cells in the core and shell encoded reward information. However, we failed to detect any differences in the percentage of neurons that encoded reward between the cocaine and control groups in either core or shell on any day (cocaine $\mathrm{X}$ day, core: $\mathrm{F}_{(2,16)}=0.41$, $\mathrm{p}=0.67$; shell: $\mathrm{F}_{(2,24)}=0.02$, $\mathrm{p}=0.98$; Figure 2B).

Previous work suggests that neurons in the NAc primarily encode rewarding outcomes with decreases in firing, while aversive outcomes are typically encoded as increases in firing [3537]. Here, the majority of neurons in both core and shell were inhibitory at the time of reward receipt (Figure 2C), but cocaine had no effect on this encoding pattern. Of all reward-encoding neurons, a similar percent of cells in the core of controls $(52 \%)$ and cocaine-treated $(52 \%)$ rats were inhibitory $\left(\chi^{2}=0, p=1\right)$, while a slightly greater proportion in both the controls $(59 \%)$ and cocaine-treated $(58 \%)$ rats were inhibitory in the shell $\left(\chi^{2}=\right.$ $0.01, \mathrm{p}=0.92$ ).

\section{Cocaine Experience Impairs Cue-Selective Encoding in the Core and Shell during First- Order Conditioning}

Next we examined neural encoding during the presentation of cues during days 1, 5 and 10 of first-order conditioning. Cue selective neurons ( $c$ trol [ $n=38]$, cocaine [ $n=12]$ ) were categorized into two types: 1 ) those only responsive during the CS+ compared to both baseline and the CS- (termed "cue-only cells"; Figure 3A, left) and 2) those responsive 
during the CS+ and also during reward delivery (i.e., termed "cue-outcome cells"; Figure $3 \mathrm{~A}$, right).

In the core, the percentage of cells encoding cue-only representations (Figure 3A, left) was unaffected by cocaine experience. Cocaine-treated rats showed similar percentages of cueonly cells as controls across days (Figure $3 \mathrm{~B}$; cocaine $\mathrm{X}$ day, $\mathrm{F}_{(2,16)}=0.03$, $\mathrm{p}=0.97$ ). In contrast, cue-only encoding in the shell was impaired following cocaine exposure (Figure $3 \mathrm{C}$; cocaine $\mathrm{X}$ day, $\left.\mathrm{F}_{(2,22)}=4.74, \mathrm{p}=0.03\right)$. While controls increased the percentage of cells encoding cue-only representations in the shell increased across days (day 1 vs day 10, $\mathrm{p}=0.0003$ ), cocaine-experienced rats failed to do so (day 1 vs day $10, \mathrm{p}=0.67$ ). Indeed, cueonly encoding was significantly lower than controls on day $5(\mathrm{p}=0.05)$ and day 10 $(\mathrm{p}=0.0003)$. Thus, cocaine experience selectively abolished cue-only representations in the shell but not the core during first-order conditioning.

In contrast, the ability to encode cue-outcome representations (i.e., both cue and outcome) was differentially impacted by cocaine experience in the core and shell. In the core, this encoding was almost entirely eliminated across all recorded days (cocaine X day, $\left.\mathrm{F}_{(2,16)}=13.61, \mathrm{p}<0.001\right)$. While controls showed significant increases in the percent of cueoutcome cells across days (day 1 vs day 10, $\mathrm{p}=0.0002$ ), cocaine animals did not (day 1 vs day $10, p=0.98$; Figure 3D). Critically, cue-outcome encoding in the core was significantly greater in controls than cocaine animals on day $5(\mathrm{p}=0.012)$ and day $10(\mathrm{p}=0.0002)$.

However, in the shell, cue-outcome encoding was moderately lower in cocaine-treated rats than controls as revealed by a main effect of drug, $\mathrm{F}_{(1,11)}=7.19$, $\mathrm{p}=0.021$, but a nonsignificant interaction between drug $\mathrm{X}$ day, $\mathrm{F}_{(2,22)}=1.94, \mathrm{p}=0.17$, indicated that there were no significant pairwise differences between groups on any of the recording days (Figure 3E). Finally, these cue encoding effects mirrored in the neural population (i.e., percent cue selective out of total cells recorded on a given day; Figure S5).

The putative role for the NAc has traditionally been that of the "limbic-motor interface" [38] in which motivationally salient information is integrated to guide behavior. If so, then in normal animals cue-selective encoding should correlate with behavioral performance. To examine this possibility for first-order conditioning, cue-outcome or cue-only cells were separately correlated with a behavioral index of learning (i.e., a normalized elevation score assessing the conditioned response to the $\mathrm{CS}+$ above the baseline and $\mathrm{CS}-$ epochs ranging from +1 [selective approach to the foodcup during $\mathrm{CS}+$ ] to -1 [selective avoidance of the foodcup during $\mathrm{CS}+$ ] and 0 indicating no conditioning; see Supplementary Methods for details). In controls, the percent of core neurons that encoded the cue-outcome association was significantly positively correlated with behavior, $r=0.49, \mathrm{~F}_{(1,26)}=8.14$, $\mathrm{p}=0.0084$, while the percent of cells that were cue-only was not, $r=0.15, \mathrm{~F}_{(1,26)}=0.57, \mathrm{p}=0.46$ (Figure $4 \mathrm{~A}$ ). Shell neurons in controls showed the opposite pattern of encoding; cue-only representations were significantly and positively correlated with behavior, $r=0.63, \mathrm{~F}_{(1,43)}=28.87, \mathrm{p}<0.0001$, but cue-outcome associations were not, $\mathrm{r}=0.21, \mathrm{~F}_{(1,43)}=2.01, \mathrm{p}=0.16$ (Figure 4B). Following cocaine experience, these representations were decoupled from behavior. In the core, neither cue-outcome, $\mathrm{r}=0.08, \mathrm{~F}_{(1,53)}=0.34, \mathrm{p}=0.56$ (Figure $4 \mathrm{C}$ ), nor cue-only encoding, $\mathrm{r}=0.03$, $\mathrm{F}_{(1,53)}=0.06, \mathrm{p}=0.81$, significantly correlated with behavior. Similarly, in the shell there was no correlation with behavior and cue-outcome, $r=0.04, \mathrm{~F}_{(1,67)}=0.10, \mathrm{p}=0.75$, or cue-only $\mathrm{r}=0.19, \mathrm{~F}_{(1,67)}=2.56, \mathrm{p}=0.11$ encoding $($ Figure 4D).

Relatedly, we assumed that if first-order associations were necessary for subsequent secondorder learning, then this encoding should predict future behavioral success in SOC. Using all subjects with valid recordings, we found that cue-selective encoding in the shell positively correlated with subsequent behavioral performance $\mathrm{SOC}, \mathrm{r}=0.64, \mathrm{~F}_{(1,9)}=6.28$, $\mathrm{p}=0.037$, but not the core, $\mathrm{F}_{(1,6)}=0.01$, n.s. 


\section{Cocaine Abolishes Neural Correlates of Second-Order Conditioning in the Shell, but Not the Core of the NAC}

Given the impairment in behavior during second-order conditioning precipitated by cocaine experience (Figure 1), we hypothesized that neural encoding during SOC (Figure 5A, top) would also be disrupted in the NAc. Surprisingly, despite poor behavioral performance during second-order conditioning in the cocaine-experienced rats, core neurons of these animals encoded SOC information similar to controls. While both showed a modest increase in SOC encoding over days, $\mathrm{F}_{(2,18)}=3.63, \mathrm{p}=0.047$, there was no main effect of cocaine, $(\mathrm{F}<1)$, or interaction of cocaine $\mathrm{X}$ day, $(\mathrm{F}<1)$ in the core (Figure 5, middle). In contrast, shell neurons were significantly less likely to encode $\mathrm{SOC}$ information after cocaine exposure (Figure 5, bottom). A main effect of cocaine, $\mathrm{F}_{(1,9)}=12.78$, $\mathrm{p}=0.006$, was followed by planned comparisons between cocaine and controls on each day, indicating a significant decrease in the cocaine group compared to controls on SOCD2 ( $\mathrm{p}=0.02)$ and a trend on SOCD3 ( $\mathrm{p}=0.053$ ). Importantly, controls showed significant increases in SOC encoding from SOCD1 to SOCD2 $(\mathrm{p}=0.045)$ and to SOCD3 $(\mathrm{p}=0.006)$, while cocaine-treated animals did not (SOCD1 vs SOCD2, $\mathrm{p}=0.91$; SOCD1 vs SOCD3, $\mathrm{p}=0.15$ ).

Finally, to understand whether this encoding was related to behavior, we correlated SOCselective encoding in core and shell with behavioral discrimination. In controls, SOC encoding in both core, $\mathrm{r}=0.63, \mathrm{~F}_{(1,9)}=5.81$, $\mathrm{p}=0.039$, and shell, $\mathrm{r}=0.53, \mathrm{~F}_{(1,12)}=4.78$, $\mathrm{p}=0.049$, were significantly and positively correlated with behavioral accuracy in the SOC task (Figure 6A). In contrast, cocaine-treated rats showed no positive correlations in the core, $\left.\mathrm{r}=0.05, \mathrm{~F}_{(1,20)}=0.067, \mathrm{p}=0.799\right)$. In the shell there was a nearly significant negative trend between SOC-selectivity and behavior, $r=-0.43, \mathrm{~F}_{(1,18)}=4.31, \mathrm{p}=0.052$ (Figure 6B), such that encoding actually decreased as SOC testing proceeded.

\section{DISCUSSION}

The present findings provide the first evidence of a critical and differential involvement of the NAc core and shell in supporting learning necessary for higher-order associations. Specifically, despite similar rates of Pavlovian behavior during first-order conditioning compared to controls, cocaine-experienced rats were subsequently unable to acquire the second-order association. This deficit was accompanied by the loss of discrete subsets of associative neural encoding in cocaine-experienced animals in both NAc core and shell when learning the first-order association. These findings suggest that as a result of cocaine experience, changes in NAc neurons are observed in which they fail to encode subsequent motivationally salient associative information, depriving animals of the ability to use this information to guide higher-order learning.

\section{Cocaine Experience Selectively Disrupts Performance of Higher-Order Conditioning}

The present findings are consistent with previous work in which cocaine impairs the ability for animals to adaptively alter ongoing behavior $[7,8,10$, 39]. For example, cocaineexperienced rats easily learned to discriminate between Pavlovian cues, but failed to alter behavior when the associated food is later devalued through illness [7]. In instrumental settings, rats with a history of cocaine acquire cue discriminations without deficit, but fail to flexibly alter behavior under reversal conditions [8-10]. Thus, cocaine-treated rats acquired appetitive behaviors but were unable to use this information under more demanding and adaptive conditions. However, the present results extend earlier findings by demonstrating that impairments may not reside in the ability to flexibly alter learned associations, but rather to successfully encode associative information during original learning. 
Notably, these impairments in cocaine-treated rats mirror those found following NAc lesions. Damage involving the NAc core blocks the ability to perform second-order conditioning, but not first-order learning [32], while damage limited to the NAc core or shell induce deficits in Pavlovian devaluation [15] and features of goal-directed action [40]. Thus, cocaine exposure induces alterations in higher-order behavior in ways that are similar to and as profound as the loss of the NAc.

\section{Neural Encoding in the NAc Tracks the Acquired Value of Predictive Cues}

A large proportion of neurons in the NAc in controls encoded information about cues over the course of learning, consistent with previous findings [24]. In control rats, cue-related encoding increased with improved performance across days of training. Indeed, cueselective encoding was almost exclusively for the CS+ (which gained motivational significance through its association with the food reward), or the SOC+ (which gained significance through association with the CS+), but almost never for the CS- or SOC-. Thus, encoding for these stimuli appeared to track important motivationally-significant information about the cues rather than their simple stimulus properties.

In cocaine-treated rats, these encoding populations were either impaired or abolished. Core and shell neurons in first-order sessions failed to encode cue-outcome or cue-only associations, respectively, both of which were strongly correlated with accurate behavior in controls. Therefore, these impoverished representations prevented rats from using information acquired during first-order conditioning to support new learning in second-order conditioning. Given that rats performed the initial discrimination accurately, these findings suggest that cocaine-experienced rats employed a different compensatory strategy to solve this task that was independent of the NAc, such as encoding a simple stimulus-response association between the CS+ and foodcup. These results support and extend earlier lesion findings which have suggested that the quality of learning in animals with limbic circuit impairments is severely compromised compared to intact controls. For example, using a similar design, pre-training lesions (e.g., BLA) induce poor performance in second-order conditioning [41, 42] and Pavlovian devaluation [43, 44], though neural disruption created after rats acquired the initial association failed to disrupt these behaviors [41, 43]. These findings reinforce the present finding that detailed associative encoding during initial learning is essential to support later aspects of higher-order behavior.

\section{Core and Shell Track Specific Features of Associative Learning}

We report here the striking finding of complementary roles for NAc core and shell in the encoding of cue associations. Specifically, in controls, core neurons preferentially encoded the relationship between cues and reinforcing outcomes, while shell neurons were more likely to encode the significance of the cue alone. These populations in their respective subregions increased with learning, and correlated with individual performance; notably, these populations were selectively abolished following cocaine experience while leaving unaffected populations that did not predict behavior in controls. However, it is not known whether preserved firing rate representations in these neurons of cocaine-treated rats could support features of behavior; future investigations will target this intriguing possibility.

These results illuminate a growing literature examining differences in NAc core and shell function [45]. By some accounts, the NAc core has been demonstrated to preferentially process more "cognitive" aspects of associative learning; lesions of the NAc core make rats insensitive to shifts in both value and outcome identity [15, 46]. While lesions do not affect the ability to select from among differently valued rewards (e.g., 1 vs 2 pellets), NAclesioned rats inappropriately failed to select the more valuable reward after it had been associated with a delay or probabilistic outcome [18-20, 47, 48]. Further, neurons in the 
core more strongly encode cue-outcome relationships than in the shell [13] and express differences in firing rates for cues predictive of preferred options during choice behavior [26], while glutamate antagonists in the core prevent responding to a food-predictive discriminative stimulus [21].

However, the present work indicates a previously underappreciated but important role for the shell in higher-order learning. Shell encoding tracked features of behavior in both firstorder and second-order sessions in controls, and both populations were abolished following cocaine experience. In contrast with the core, the shell has been more strongly associated with simpler forms of encoding, such as tracking reward magnitude [19, 49]. For example, one previous study showed that neurons tracked a rewarding discriminative stimulus similarly to core, but transient inhibition of this region failed to disrupt behavior for the cue [21]. In contrast, we and others have shown that shell is important for mediating changes in motivational behavior in Pavlovian-to-instrumental (PIT) tasks [13, 50-52]. For example, we recently demonstrated that cocaine experience enhanced the PIT effect, and that shell neurons - but not core - tracked this potentiated behavior [13]. Notably, in that study, taskrelated encoding in the shell was potentiated, in contrast with the present findings where they were almost abolished. This pattern is consistent with the animals' training; in the PIT study, rats were trained in a drug-naïve state, and only after this did they undergo cocaine self-administration and subsequent PIT. This suggests that cocaine experience with alreadylearned associative information may "stamp in" and even enhance these representations, while cocaine experience prior to learning may bias encoding away from NAc structures. This suggests information acquired prior to (or during) chronic cocaine abuse may have privileged access towards guiding behavior, while information acquired after cocaine experience may have difficulty accessing normal limbic structures necessary for flexible behavior. As such, these more habitual representations may provide a basis for patterns of relapse and cycles of continued abuse.

\section{Reward encoding is not affected by cocaine exposure}

Rats with a history of cocaine self-administration showed normal rates of motivational behavior to obtain food rewards, as both food-directed consummatory behavior and neural encoding of reward in core and shell were indistinguishable from controls. Compellingly, the encoding in both controls and cocaine animals showed a preponderance of inhibitory encoding during food consumption, a feature that has been demonstrated to indicate rewarding motivational value $[35,37,53]$. Thus, in this study, cocaine did not devalue rewards compared to drug, but instead impaired the ability to learn appropriate associations between predictive cues and valued outcomes [54].

\section{Dopaminergic Function in NAc Encoding}

NAc receives a dense DA projection primarily from discrete regions of the VTA [55], and DA signaling has been widely implicated in supporting associative learning, including second-order conditioning [56]. Indeed, the relationship between DA signaling and neural encoding in NAc appears correlated [57, 58], while loss of phasic DA release impairs appropriate NAc encoding $[59,60]$. Thus, it is of note that in rats with repeated cocaine experience, DA release and reuptake dynamics were impaired compared to controls [61], suggesting that cocaine may induce deficits in encoding through DA-mediated mechanisms; future investigations will explore this important possibility.

\section{Supplementary Material}

Refer to Web version on PubMed Central for supplementary material. 


\section{Acknowledgments}

This research was supported by DA028156 to MPS and DA014339 to RMC.

\section{References}

1. Everitt BJ, Parkinson JA, Olmstead MC, Arroyo M, Robledo P, Robbins TW. Associative processes in addiction and reward. The role of amygdala-ventral striatal subsystems. Ann N Y Acad Sci. 1999; 877:412-38. [PubMed: 10415662]

2. Takahashi Y, Roesch MR, Stalnaker TA, Schoenbaum G. Cocaine exposure shifts the balance of associative encoding from ventral to dorsolateral striatum. Front Integr Neurosci. 2007; 1:11. [PubMed: 18958239]

3. Volkow ND, Wang GJ, Telang F, Fowler JS, Logan J, Childress AR, Jayne M, et al. Cocaine cues and dopamine in dorsal striatum: Mechanism of craving in cocaine addiction. J Neurosci. 2006; 26(24):6583-8. [PubMed: 16775146]

4. Koob GF. The role of the striatopallidal and extended amygdala systems in drug addiction. Annals of the New York Academy of Sciences. 1999; 877:445-60. [PubMed: 10415664]

5. LaLumiere RT, Smith KC, Kalivas PW. Neural circuit competition in cocaine-seeking: Roles of the infralimbic cortex and nucleus accumbens shell. Eur J Neurosci. 2012; 35(4):614-22. [PubMed: 22321070]

6. Smith KS, Berridge KC, Aldridge JW. Disentangling pleasure from incentive salience and learning signals in brain reward circuitry. Proc Natl Acad Sci U S A. 2011; 108(27):E255-64. [PubMed: 21670308]

7. Schoenbaum G, Setlow B. Cocaine makes actions insensitive to outcomes but not extinction: Implications for altered orbitofrontal-amygdalar function. Cerebral Cortex. 2005

8. Stalnaker TA, Roesch MR, Franz TM, Calu DJ, Singh T, Schoenbaum G. Cocaine-induced decision-making deficits are mediated by miscoding in basolateral amygdala. Nat Neurosci. 2007; 10(8):949-51. [PubMed: 17603478]

9. Calu DJ, Stalnaker TA, Franz TM, Singh T, Shaham Y, Schoenbaum G. Withdrawal from cocaine self-administration produces long-lasting deficits in orbitofrontal-dependent reversal learning in rats. Learn Mem. 2007; 14(5):325-8. [PubMed: 17522022]

10. Schoenbaum G, Saddoris MP, Ramus SJ, Shaham Y, Setlow B. Cocaine-experienced rats exhibit learning deficits in a task sensitive to orbitofrontal cortex lesions. European Journal of Neuroscience. 2004; 19(7):1997-2002. [PubMed: 15078575]

11. Wyvell CL, Berridge KC. Incentive sensitization by previous amphetamine exposure: Increased cue-triggered "wanting" for sucrose reward. J Neurosci. 2001; 21(19):7831-40. [PubMed: 11567074]

12. Ranaldi R, Egan J, Kest K, Fein M, Delamater AR. Repeated heroin in rats produces locomotor sensitization and enhances appetitive pavlovian and instrumental learning involving food reward. Pharmacol Biochem Behav. 2009; 91(3):351-7. [PubMed: 18755208]

13. Saddoris MP, Stamatakis A, Carelli RM. Neural correlates of pavlovian-to-instrumental transfer in the nucleus accumbens shell are selectively potentiated following cocaine self-administration. Eur J Neurosci. 2011; 33(12):2274-87. [PubMed: 21507084]

14. Corbit LH, Balleine BW. The general and outcome-specific forms of pavlovian-instrumental transfer are differentially mediated by the nucleus accumbens core and shell. J Neurosci. 2011; 31(33):11786-94. [PubMed: 21849539]

15. Singh T, McDannald MA, Haney RZ, Cerri DH, Schoenbaum G. Nucleus accumbens core and shell are necessary for reinforcer devaluation effects on pavlovian conditioned responding. Front Integr Neurosci. 2010; 4:126. [PubMed: 21088698]

16. Gill TM, Castaneda PJ, Janak PH. Dissociable roles of the medial prefrontal cortex and nucleus accumbens core in goal-directed actions for differential reward magnitude. Cereb Cortex. 2010; 20(12):2884-99. [PubMed: 20308201] 
17. Bezzina G, Cheung TH, Asgari K, Hampson CL, Body S, Bradshaw CM, Szabadi E, et al. Effects of quinolinic acid-induced lesions of the nucleus accumbens core on inter-temporal choice: A quantitative analysis. Psychopharmacology (Berl). 2007; 195(1):71-84. [PubMed: 17659381]

18. Cardinal RN, Howes NJ. Effects of lesions of the nucleus accumbens core on choice between small certain rewards and large uncertain rewards in rats. BMC Neurosci. 2005; 6:37. [PubMed: 15921529]

19. Stopper CM, Floresco SB. Contributions of the nucleus accumbens and its subregions to different aspects of risk-based decision making. Cogn Affect Behav Neurosci. 2011; 11(1):97-112. [PubMed: 21264647]

20. Ghods-Sharifi S, Floresco SB. Differential effects on effort discounting induced by inactivations of the nucleus accumbens core or shell. Behav Neurosci. 2010; 124(2):179-91. [PubMed: 20364878]

21. Ambroggi F, Ghazizadeh A, Nicola SM, Fields HL. Roles of nucleus accumbens core and shell in incentive-cue responding and behavioral inhibition. J Neurosci. 2011; 31(18):6820-30. [PubMed: 21543612]

22. Jones JL, Day JJ, Wheeler RA, Carelli RM. The basolateral amygdala differentially regulates conditioned neural responses within the nucleus accumbens core and shell. Neuroscience. 2010; 169(3):1186-98. [PubMed: 20570714]

23. Jones JL, Wheeler RA, Carelli RM. Behavioral responding and nucleus accumbens cell firing are unaltered following periods of abstinence from sucrose. Synapse. 2008; 62(3):219-28. [PubMed: 18088061]

24. Setlow B, Schoenbaum G, Gallagher M. Neural encoding in ventral striatum during olfactory discrimination learning. Neuron. 2003; 38(4):625-36. [PubMed: 12765613]

25. Day JJ, Wheeler RA, Roitman MF, Carelli RM. Nucleus accumbens neurons encode pavlovian approach behaviors: Evidence from an autoshaping paradigm. Eur J Neurosci. 2006; 23(5):134151. [PubMed: 16553795]

26. Day JJ, Jones JL, Carelli RM. Nucleus accumbens neurons encode predicted and ongoing reward costs in rats. Eur J Neurosci. 2011; 33(2):308-21. [PubMed: 21198983]

27. Roesch MR, Singh T, Brown PL, Mullins SE, Schoenbaum G. Ventral striatal neurons encode the value of the chosen action in rats deciding between differently delayed or sized rewards. $\mathrm{J}$ Neurosci. 2009; 29(42):13365-76. [PubMed: 19846724]

28. Aragona BJ, Cleaveland NA, Stuber GD, Day JJ, Carelli RM, Wightman RM. Preferential enhancement of dopamine transmission within the nucleus accumbens shell by cocaine is attributable to a direct increase in phasic dopamine release events. J Neurosci. 2008; 28(35):882131. [PubMed: 18753384]

29. Lecca D, Cacciapaglia F, Valentini V, Acquas E, Di Chiara G. Differential neurochemical and behavioral adaptation to cocaine after response contingent and noncontingent exposure in the rat. Psychopharmacology (Berl). 2007; 191(3):653-67. [PubMed: 16932924]

30. Holland PC, Rescorla RA. Second-order conditioning with food unconditioned stimulus. J Comp Physiol Psychol. 1975; 88(1):459-67. [PubMed: 1120816]

31. Rescorla RA. Aspects of the reinforcer learned in second-order pavlovian conditioning. J Exp Psychol Anim Behav Process. 1979; 5(1):79-95. [PubMed: 528880]

32. Setlow B, Holland PC, Gallagher M. Disconnection of the basolateral amygdala complex and nucleus accumbens impairs appetitive pavlovian second-order conditioned responses. Behav Neurosci. 2002; 116(2):267-75. [PubMed: 11996312]

33. McDannald MA, Setlow B, Holland PC. Effects of ventral striatal lesions on first- and secondorder appetitive conditioning. European Journal of Neuroscience. 2013

34. Chang SE, Wheeler DS, Holland PC. Roles of nucleus accumbens and basolateral amygdala in autoshaped lever pressing. Neurobiol Learn Mem. 2012; 97(4):441-51. [PubMed: 22469749]

35. Wheeler RA, Twining RC, Jones JL, Slater JM, Grigson PS, Carelli RM. Behavioral and electrophysiological indices of negative affect predict cocaine self-administration. Neuron. 2008; 57(5):774-85. [PubMed: 18341996]

36. Roitman MF, Wheeler RA, Carelli RM. Nucleus accumbens neurons are innately tuned for rewarding and aversive taste stimuli, encode their predictors, and are linked to motor output. Neuron. 2005; 45(4):587-97. [PubMed: 15721244] 
37. Taha SA, Fields HL. Inhibitions of nucleus accumbens neurons encode a gating signal for rewarddirected behavior. J Neurosci. 2006; 26(1):217-22. [PubMed: 16399690]

38. Mogenson GJ, Jones DL, Yim CY. From motivation to action: Functional interface between the limbic system and the motor system. Prog Neurobiol. 1980; 14(2-3):69-97. [PubMed: 6999537]

39. Mendez IA, Montgomery KS, LaSarge CL, Simon NW, Bizon JL, Setlow B. Long-term effects of prior cocaine exposure on morris water maze performance. Neurobiol Learn Mem. 2008; 89(2): 185-91. [PubMed: 17904876]

40. Schoenbaum G, Setlow B. Lesions of nucleus accumbens disrupt learning about aversive outcomes. Journal of Neuroscience. 2003; 23(30):9833-41. [PubMed: 14586012]

41. Setlow B, Gallagher M, Holland PC. The basolateral complex of the amygdala is necessary for acquisition but not expression of cs motivational value in appetitive pavlovian second-order conditioning. European Journal of Neuroscience. 2002; 15(11):1841-53. [PubMed: 12081664]

42. Hatfield T, Han JS, Conley M, Gallagher M, Holland P. Neurotoxic lesions of basolateral, but not central, amygdala interfere with pavlovian second-order conditioning and reinforcer devaluation effects. Journal of Neuroscience. 1996; 16(16):5256-65. [PubMed: 8756453]

43. Pickens CL, Saddoris MP, Setlow B, Gallagher M, Holland PC, Schoenbaum G. Different roles for orbitofrontal cortex and basolateral amygdala in a reinforcer devaluation task. Journal of Neuroscience. 2003; 23(35):11078-84. [PubMed: 14657165]

44. Johnson AW, Gallagher M, Holland PC. The basolateral amygdala is critical to the expression of pavlovian and instrumental outcome-specific reinforcer devaluation effects. J Neurosci. 2009; 29(3):696-704. [PubMed: 19158296]

45. Saddoris MP, Sugam JA, Cacciapaglia F, Carelli CM. Rapid dopamine dynamics in the accumbens core and shell: Learning and action. Frontiers in Bioscience. 2013

46. McDannald MA, Lucantonio F, Burke KA, Niv Y, Schoenbaum G. Ventral striatum and orbitofrontal cortex are both required for model-based, but not model-free, reinforcement learning. J Neurosci. 2011; 31(7):2700-5. [PubMed: 21325538]

47. Cardinal RN, Cheung TH. Nucleus accumbens core lesions retard instrumental learning and performance with delayed reinforcement in the rat. BMC Neurosci. 2005; 6:9. [PubMed: 15691387]

48. Cardinal RN, Pennicott DR, Sugapathala SL, Robbins TW, Everitt BJ. Impulsive choice induced in rats by lesions of the nucleus accumbens core. Science. 2001; 292:2499-2501. [PubMed: 11375482]

49. Remus ML, Thiels E. Stimulus-specific and differential distribution of activated extracellular signal-regulated kinase in the nucleus accumbens core and shell during pavlovian-instrumental transfer. Brain Struct Funct. 2012

50. Lex A, Hauber W. Dopamine d1 and d2 receptors in the nucleus accumbens core and shell mediate pavlovian-instrumental transfer. Learn Mem. 2008; 15(7):483-91. [PubMed: 18626092]

51. Corbit LH, Muir JL, Balleine BW. The role of the nucleus accumbens in instrumental conditioning: Evidence of a functional dissociation between accumbens core and shell. J Neurosci. 2001; 21(9):3251-60. [PubMed: 11312310]

52. Wyvell CL, Berridge KC. Intra-accumbens amphetamine increases the conditioned incentive salience for sucrose reward: Enhancement of reward wanting without enhanced liking or response reinforcement. Journal of Neuroscience. 2000; 20:8122-8130. [PubMed: 11050134]

53. Taha SA, Fields HL. Encoding of palatability and appetitive behaviors by distinct neuronal populations in the nucleus accumbens. J Neurosci. 2005; 25(5):1193-202. [PubMed: 15689556]

54. O'Brien MS, Anthony JC. Risk of becoming cocaine dependent: Epidemiological estimates for the united states, 2000-2001. Neuropsychopharmacology. 2005; 30(5):1006-18. [PubMed: 15785780]

55. Ikemoto S. Dopamine reward circuitry: Two projection systems from the ventral midbrain to the nucleus accumbens-olfactory tubercle complex. Brain Res Rev. 2007; 56(1):27-78. [PubMed: 17574681]

56. Pan WX, Schmidt R, Wickens JR, Hyland BI. Dopamine cells respond to predicted events during classical conditioning: Evidence for eligibility traces in the reward-learning network. Journal of Neuroscience. 2005; 25(26):6235-42. [PubMed: 15987953] 
57. Owesson-White CA, Ariansen J, Stuber GD, Cleaveland NA, Cheer JF, Wightman RM, Carelli RM. Neural encoding of cocaine-seeking behavior is coincident with phasic dopamine release in the accumbens core and shell. Eur J Neurosci. 2009; 30(6):1117-27. [PubMed: 19735286]

58. Cheer JF, Aragona BJ, Heien ML, Seipel AT, Carelli RM, Wightman RM. Coordinated accumbal dopamine release and neural activity drive goal-directed behavior. Neuron. 2007; 54(2):237-44. [PubMed: 17442245]

59. Cacciapaglia F, Wightman RM, Carelli RM. Rapid dopamine signaling differentially modulates distinct microcircuits within the nucleus accumbens during sucrose-directed behavior. J Neurosci. 2011; 31(39):13860-13869. [PubMed: 21957248]

60. Yun IA, Wakabayashi KT, Fields HL, Nicola SM. The ventral tegmental area is required for the behavioral and nucleus accumbens neuronal firing responses to incentive cues. Journal of Neuroscience. 2004; 24(12):2923-2933. [PubMed: 15044531]

61. Calipari ES, Ferris MJ, Melchior JR, Bermejo K, Salahpour A, Roberts DC, Jones SR. Methylphenidate and cocaine self-administration produce distinct dopamine terminal alterations. Addict Biol. 2012 
A

First-Order Conditioning (10 Days)

\begin{tabular}{|c|c|c|}
\hline Baseline & Light A (CS+) & Reward \\
\hline Baseline & Light $\mathrm{A}(\mathrm{CS}+)$ & No Reward \\
\hline Baseline & Light B (CS-) & No Reward \\
\hline
\end{tabular}

Second-Order Conditioning (3 Days)

\begin{tabular}{|c|c|c|c|}
\hline Baseline & Audio A (SOC+) & Light A (FOC+) & No Reward \\
\hline Baseline & Audio B (SOC-) & Light B (FOC-) & No Reward \\
\hline
\end{tabular}
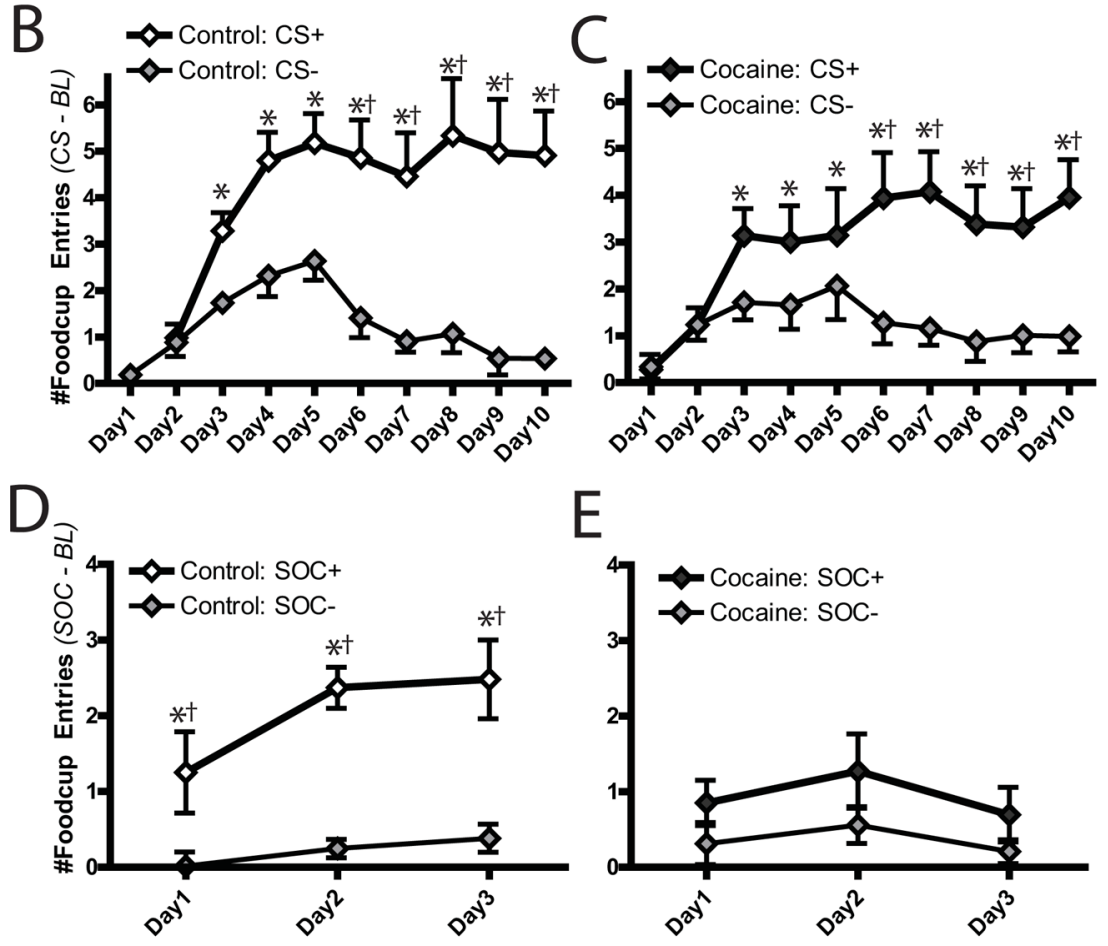

E

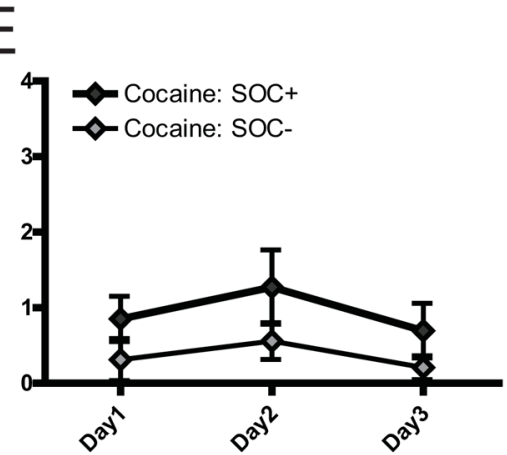

Figure 1.

Behavioral performance in first-order and second-order conditioning. (A) In first order conditioning, rats received paired presentations of a light cue $(\mathrm{CS}+)$ that co-terminated in the delivery of food (R) while another light cue (CS-) never resulted in food delivery. After 10d of first-order training, rats learned a second-order pairing for 3 days in which one audio cue $(\mathrm{SOC}+)$ predicted the delivery of the previously food-paired first-order cue (FOC+), while a different audio cue (SOC-) co-terminated with the delivery of the other first-order cue never paired with food (FOC-). No food was delivered during this SOC/FOC pairings. Cocaine experience had no apparent effect on first-order behavior. Rats in both the control group (B) and cocaine group $(\mathrm{C})$ displayed similar cue discrimination between the $\mathrm{CS}+$ and $\mathrm{CS}-$. In contrast, cocaine experience profoundly impaired learning the second-order association (E) compared to controls (D). ${ }^{*} \mathrm{CS}+>$ baseline $(\mathrm{p}<0.01) ; \dagger \mathrm{CS}+>\mathrm{CS}-(\mathrm{p}<0.01)$. 

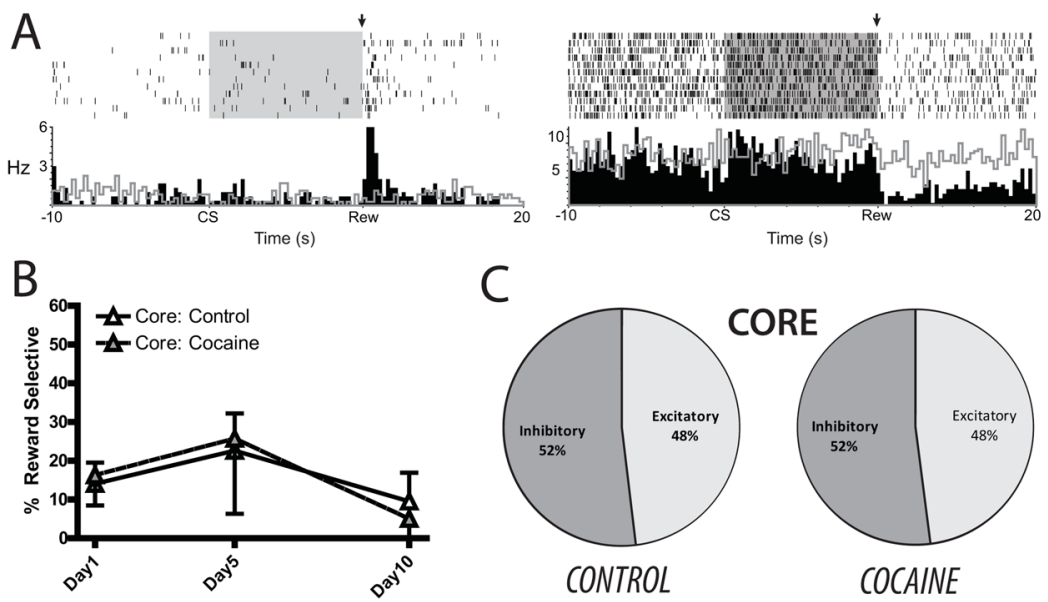

$\mathrm{C}$

Time (s)
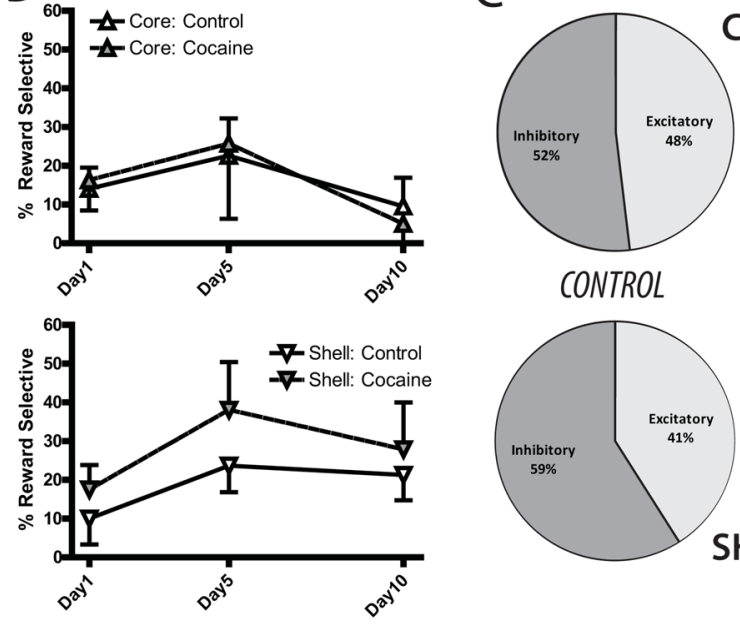

CORE

CONTROL
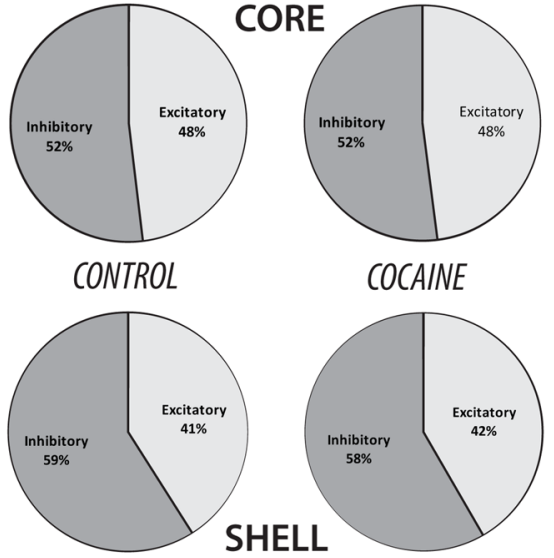

COCAINE

Figure 2.

Natural reward encoding in the NAc was not disrupted by cocaine experience. (A).

Representative neurons show either a phasic excitation (left) or phasic inhibition (right) to the receipt of the food reward. Raster plots and black histograms (averaged by $250 \mathrm{~ms}$ bins) show firing patterns in during CS+ trials, while the gray outline shows the histogram for CS - encoding by the same neuron. The arrow above the rasters indicates where food is delivered. (B) Cocaine experience did not affect the percent of reward-selective encoding in the core (top) or shell (bottom) on any day of training. (C) In the core (top) and shell (bottom), there were nearly identical percentages of excitations and inhibitions to reward delivery in controls (left) and cocaine experienced animals (right). Rew $=$ reward delivery here and in subsequent figures. 


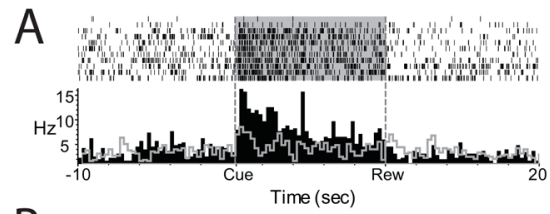

B
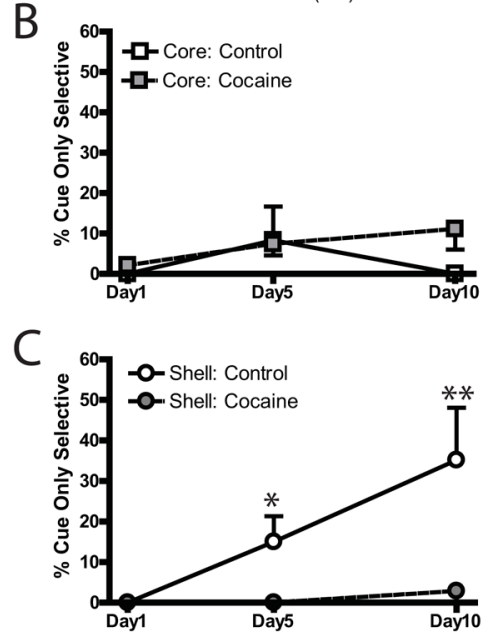

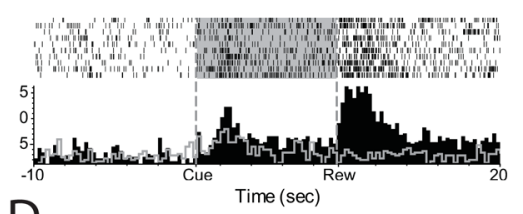

D $60-\square$-Core: Control

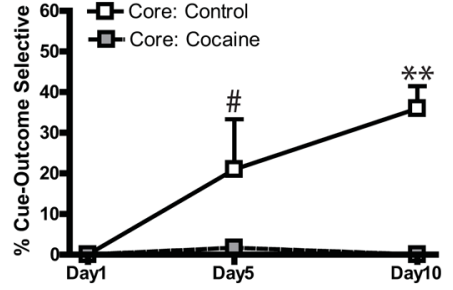

E

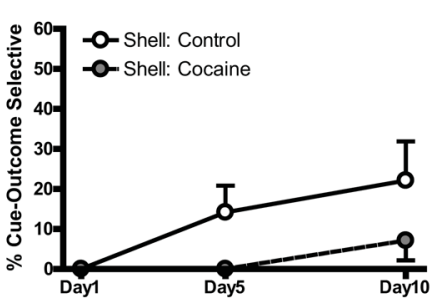

Figure 3.

Cue-selective encoding during first-order conditioning in the core and shell is impaired following cocaine experience. (A) Example cue-only neuron (left) shows selective excitatory activity during the CS+ (raster, black bars) but not the CS- (gray histogram line) aligned to CS onset, while example cue-outcome neuron (right) displays significant excitations to both the CS+ and reward receipt. The mean percent of cue-only encoding cells were unaffected by cocaine experience in the core (B), but were abolished in the shell following cocaine exposure (C). In contrast, cue-outcome cells were selectively abolished in the core following cocaine experience (D), but only modestly impaired in the shell (E). \#p < $0.06, * \mathrm{p}<0.02, * * \mathrm{p}<0.01, \mathrm{CS}+>\mathrm{CS}-$. 

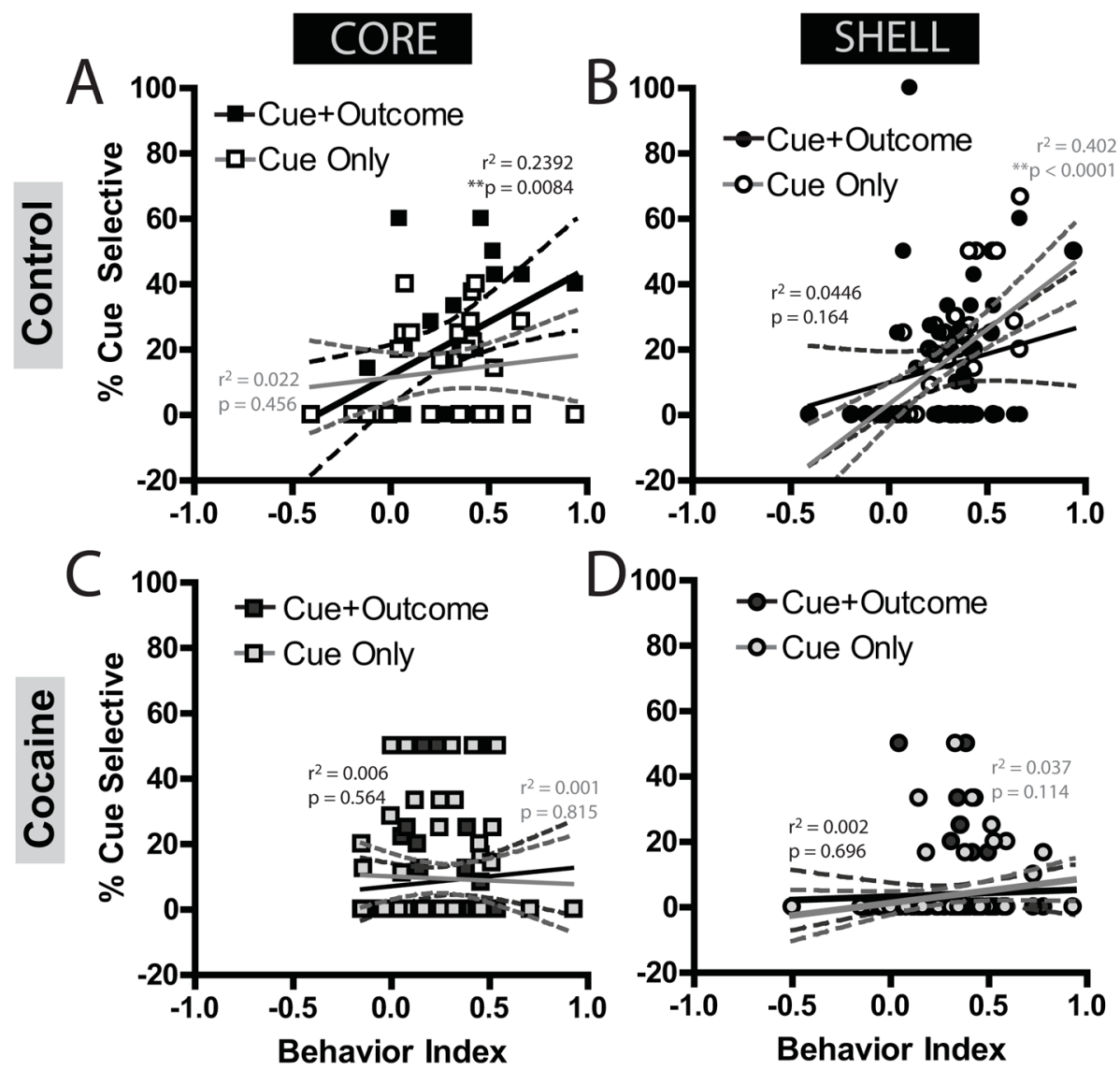

Figure 4.

Correlations between behavior and first-order encoding by NAc neurons in the core and shell. Behavioral index ranged from -1 to +1 , with 0 being no discrimination, and +1 indicating increases in foodcup behavior selective to the CS+. In controls, core encoding of cue-outcome associations correlated with behavior, while cue-only encoding $\operatorname{did}$ not (A). In the shell, behavior correlated with cue-only encoding but not the cue-outcome associations (B). However, cocaine-experienced rats showed no correlations of either cue-encoding subpopulation with behavior in either the core (C) or shell (D). 

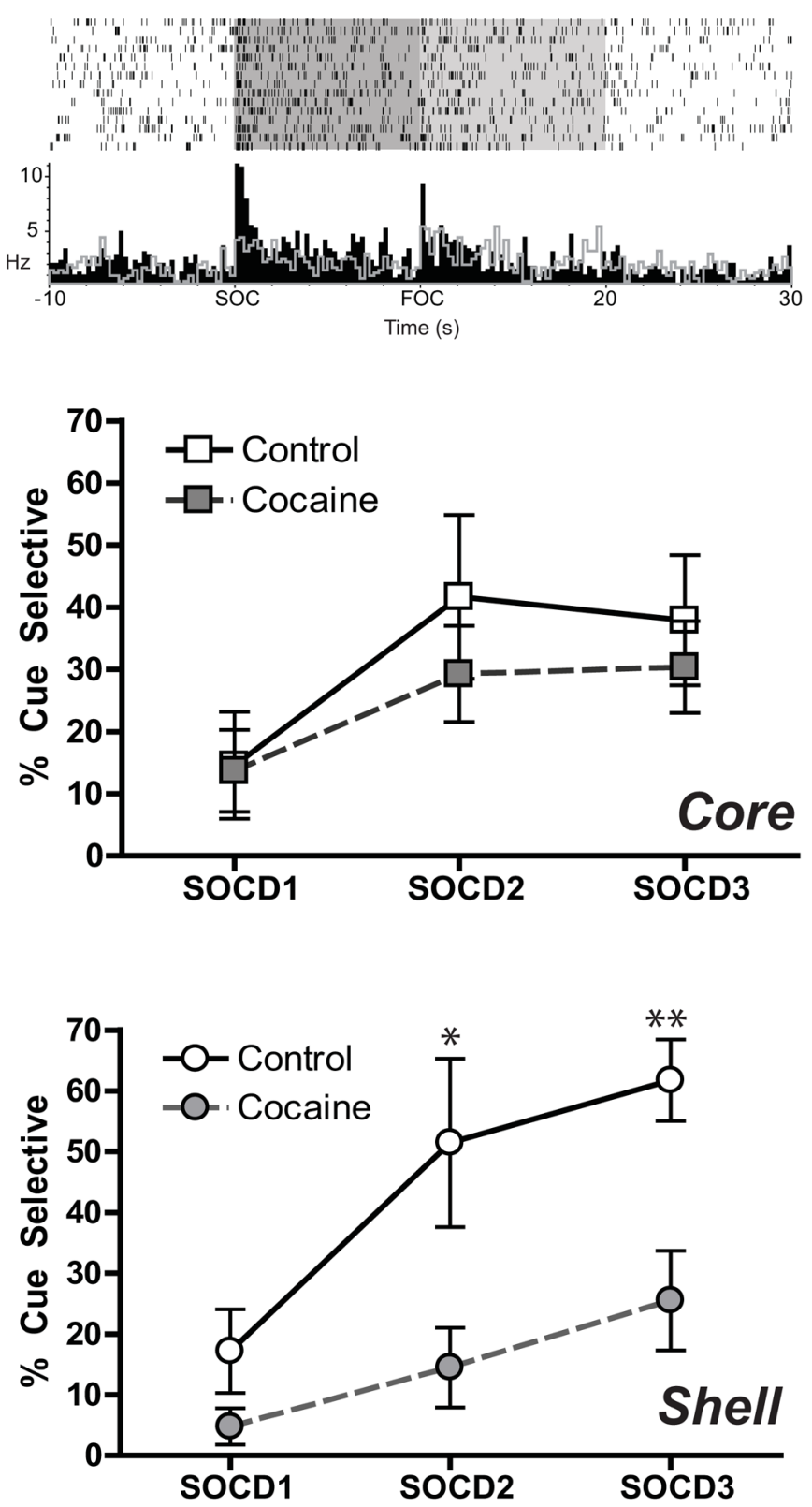

Figure 5.

Cue-selective encoding in core and shell during second-order conditioning. (Top) Example neuron of a SOC encoding cell shows selective excitatory firing during the SOC+ (black histogram bars) compared to the SOC- (gray histogram line). In the core (middle), the percentage of cells encoding the SOC+ was similar in the controls and cocaine rats across days. In contrast, in the shell (bottom), SOC encoding was significantly attenuated after cocaine. $* \mathrm{p}<0.05 ; * \mathrm{*}<0.01$. 

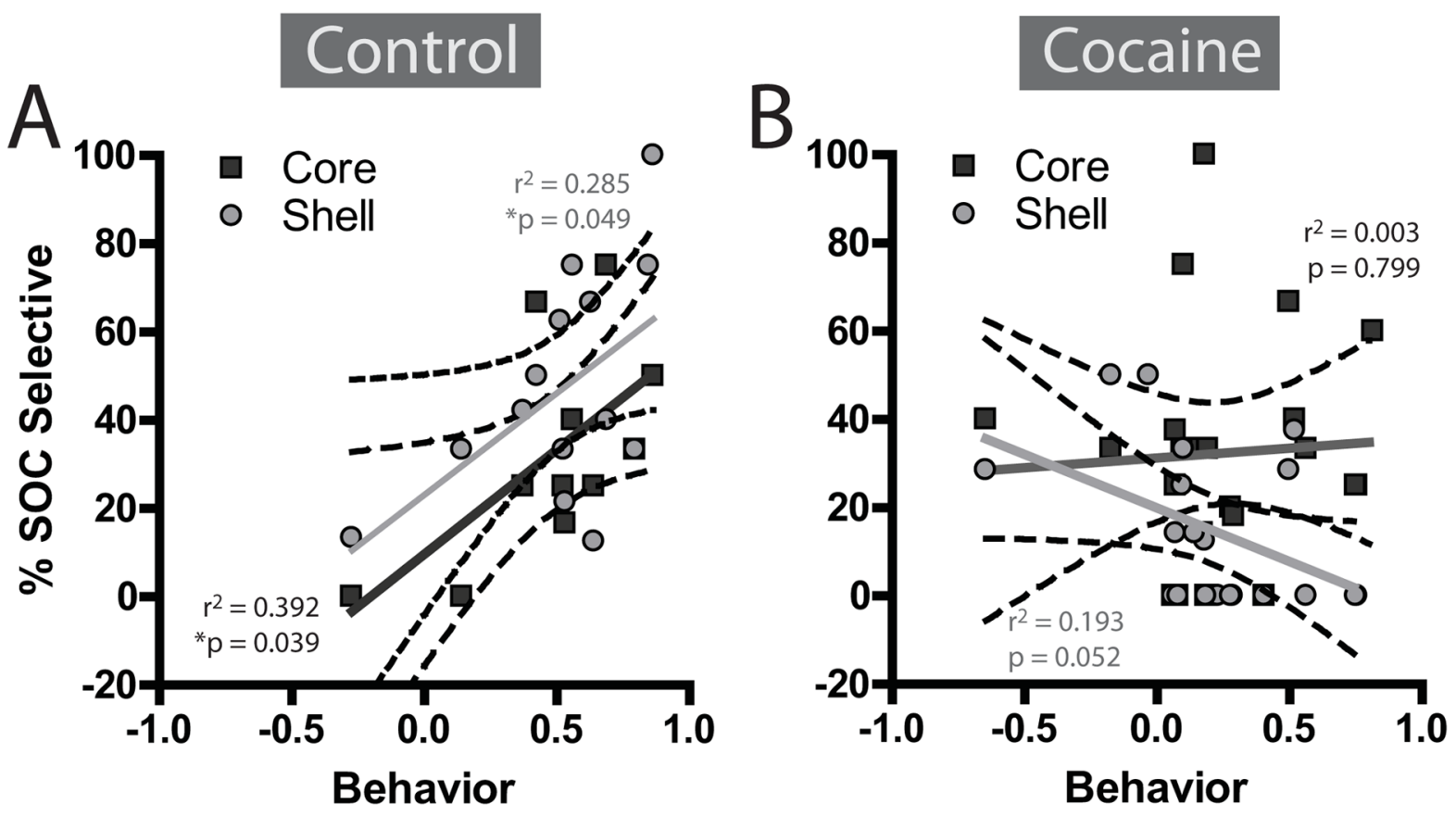

Figure 6.

The percentage of neurons encoding the SOC+ during second-order conditioning significantly correlated with discriminative behavior in controls in both core and shell (A). However, in cocaine rats, there were no reliable positive correlations between behavior and SOC-selective encoding (B). 